\title{
Effects of thermal stratification and mixing on reservoir water quality
}

\author{
Şebnem Elçi
}

Received: 2 July 2007/Accepted: 21 January 2008/Published online: 22 March 2008

(C) The Japanese Society of Limnology 2008

\begin{abstract}
In this study, the effect of thermal stratification on water quality in a reservoir has been investigated by field observations and statistical analysis. During the summer period, when stratification is evident, field observations indicate that the observed dissolved oxygen concentrations drop well below the standard limit of $5 \mathrm{mg}^{-1}$ at the thermocline, leading to the development of anoxia. The reasons for variations in the dissolved oxygen concentrations were investigated. Variations of air temperature and other meteorological factors and lateral flows from side arms of the lake were found to be responsible for the increase of dissolved oxygen concentrations. It was also observed that turbidity peaked mostly in the thermocline region, closely related to the location of the maximum density gradient and thus low turbulence stabilizing the sediments in the vertical water column. Relatively cold sediment-laden water flowing into the lake after rain events also resulted in increased turbidity at the bottom of the lake. Nondimensional analysis widely used in the literature was used to identify the strength of the stratification, but this analysis alone was found insufficient to describe the evolution of dissolved oxygen and turbidity in the water column. Thus correlation of these parameters was investigated by multivariate analysis. Fall (partial mixing), summer (no mixing), and winter (well mixed) models describe the correlation structures between the independent variables (meteorological parameters) and the dependent variables (water-quality parameters). Statistical analysis results indicate that air temperature, one day lagged wind
\end{abstract}

Ş. Elçi $(\bowtie)$

Department of Civil Engineering, Izmir Institute of Technology, Gülbahçe Campus, Urla, 35437 Izmir, Turkey

e-mail: sebnemelci@iyte.edu.tr speed, and low humidity affected variation of water-quality parameters.

Keywords Thermal stratification - Water quality . Multivariate analysis · Dissolved oxygen · Turbidity

\section{Introduction}

In a reservoir, wind-induced currents and the structure of the thermocline mainly control the vertical distribution of heat, dissolved substances, and nutrients in the water column. Understanding lake hydrodynamics is important for management of water resources, and thermal stratification is of great importance for the pattern of mixing in lakes and reservoirs.

Stratification during the summer acts as a barrier restraining mixing of the water column. The warm water in the epilimnion is unable to move through the cold, dense water of the hypolimnion. As a result of incomplete mixing of the water column and lack of light for the photosynthesis at the hypolimnion, the water column can become anoxic.

This study was motivated by the degradation of water quality in the summer because of thermal stratification, as observed in many reservoirs and lakes around the world. Tahtali Lake, providing $40 \%$ of its fresh water to Izmir, Turkey, was selected as study site, because the lake experienced dense stratification during the summer months leading to deterioration of water quality.

The objective of this study was to investigate the structure of the thermal stratification, its relationship to wind and flow conditions, and its effect on water-quality parameters including dissolved oxygen and suspended sediment concentrations. Existing studies have primarily focussed on developing water-quality models, in which the 
physical processes of transport and mixing within the water body have generally been oversimplified, or on extending hydrodynamic models to include water-quality components by combining them with simple input-output models (Hamilton and Schladow 1997). Numerical models developed by Bell et al. (2006), Stefan and Fang (1994), Bonnet et al. (2000) are among the various models developed for simulating temperature and dissolved oxygen in lakes. However most of the studies in the literature lack the extensive field measurements required for investigation of the meteorological factors affecting water-quality variations. Within the scope of this study, monthly measurements were conducted and the impact of these factors on stratification and on water-quality parameters was investigated.

In this study, the factors causing mixing of the water column were investigated by nondimensional analysis (Imberger 1998) which determines the degree of stability and mixing in the lake. The water-quality index (Waterresearch 2006a) was also used to assess overall water quality in the lake during the winter and summer periods.

Motivated by the water-quality index results, field observations were conducted monthly in the vertical water column where water-quality parameters and temperature profiles were measured. To examine the behaviour of the parameters further, measurements over a longer period (1 month) were made, during which data were recorded internally every half an hour. Results were analyzed by statistical analysis. Simca-P 10.5 software (Umetrics 2003) was used for multivariate analysis of the water-quality parameters.

\section{Study site}

The observations were conducted in Tahtali Reservoir, Menderes, Turkey $\left(38^{\circ} 15^{\prime} \mathrm{N}, 27^{\circ} 28^{\prime} \mathrm{E}\right)$. Tahtali Dam was projected as a rockfill dam and completed in 1996 to supply fresh water to Izmir, the third largest metropolitan area with a population of over 3 million. The capacity of the dam is 175 million $\mathrm{m}^{3}$ and it generates a total of 5 million $\mathrm{m}^{3}$ water monthly with an average water discharge of $3 \mathrm{~m}^{3} \mathrm{~s}^{-1}$. The dam is currently operated by Izmir Water and Sewage Administration (IZSU).

Lake Tahtali has a surface area of $20 \mathrm{~km}^{2}$, a mean depth of $15 \mathrm{~m}$, and a maximum depth of $27 \mathrm{~m}$. The lake is located $60 \mathrm{~m}$ above sea level. The major inflows are from the north via Sasal Stream (Murat Stream and Dari Stream) and Tahtali Stream (Fig. 1). Discharge of the other four tributaries is negligible. The only outflow point is at the Southwest location of the lake from the deepest area, corresponding to $27 \mathrm{~m}$. The water is provided as drinking water for city of Izmir after being treated.

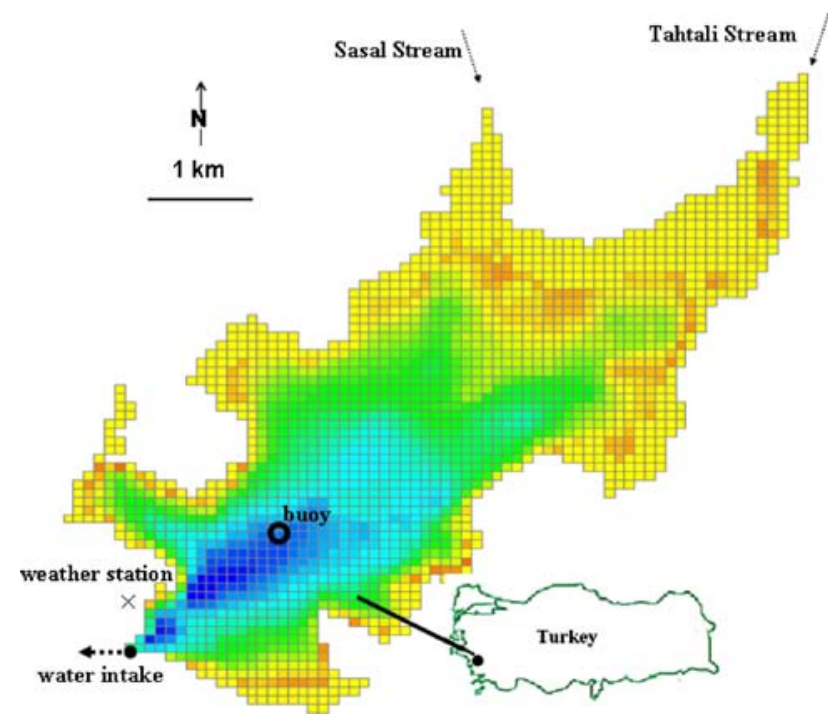

Fig. 1 Bathymetric map of Lake Tahtali. The darker area represents the deepest region of the lake corresponding to $27 \mathrm{~m}$. The buoy, where stationary measurements were made, is shown by a circle

The site is exposed to the full force of wind blowing mostly from East and also from the North. The average annual wind speed is $3 \mathrm{~m} \mathrm{~s}^{-1}$. The locale has a Mediterranean climate, with average annual temperatures for the warmest month, July, of $28^{\circ} \mathrm{C}$ and for the coldest month, January, of $8^{\circ} \mathrm{C}$.

\section{Instrumentation}

A water-quality meter (WQC) was used to measure turbidity by the scattered light measurement method. Turbidity is measured by reading of the amount of scattered light and is expressed in terms of the optical property causing the light beam passing through the sample of fluid to be scattered and absorbed rather than transmitted. The relationship between suspended solids in the liquid and light intensity due to particle scatter is determined by calibration of the instrument.

Data collection in Lake Tahtali was achieved from a boat stationed at a buoy (depth $19 \mathrm{~m}$ ), where the WQC-24 water-quality meter designed by TOA-DKK was used for measurements. The instrument is capable of measuring water-quality parameters $(\mathrm{pH}$, conductivity, salinity, dissolved oxygen, turbidity, temperature) and a depth sensor is attached.

Meteorological data were acquired from a weather station designed by TFA (Master Touch) located on the southwest shoreline of Lake Tahtali (Fig. 1). The data collected at this weather station included air pressure, air temperature, humidity, solar radiation, wind speed, wind direction, and rain. Evaporation data were provided by IZSU. 
Table 1 Parameters used to determine the water-quality index for Tahtali Lake

\begin{tabular}{|c|c|c|c|c|c|c|c|}
\hline Parameter & $\begin{array}{l}\text { Measured } \\
\text { value } \\
\text { (April) }\end{array}$ & $\begin{array}{l}\text { Quality } \\
\text { index } \\
\text { value }\end{array}$ & $\begin{array}{l}\text { Measured } \\
\text { value } \\
\text { (August) }\end{array}$ & $\begin{array}{l}\text { Quality } \\
\text { index } \\
\text { value }\end{array}$ & $\begin{array}{l}\text { Weighting } \\
\text { factor }\end{array}$ & $\begin{array}{l}\text { Total } \\
\text { (April) }\end{array}$ & $\begin{array}{l}\text { Total } \\
\text { (August) }\end{array}$ \\
\hline DO & $70 \%$ & 75 & $22 \%$ & 13 & 0.17 & 12.75 & 2.21 \\
\hline Faecal coliform & - & & - & & 0.16 & - & - \\
\hline $\mathrm{pH}$ & 8 & 84 & 7.9 & 88 & 0.11 & 9.24 & 9.68 \\
\hline BOD & 3 & 67 & 10 & 34 & 0.11 & 7.37 & 3.74 \\
\hline $\begin{array}{r}\text { Temperature } \\
\text { difference }\end{array}$ & 2 & 85 & 4 & 77 & 0.10 & 8.50 & 7.7 \\
\hline Total phosphate & - & & - & & 0.10 & - & - \\
\hline Nitrate & 0.7 & 96 & 0.2 & 97 & 0.10 & 9.6 & 9.7 \\
\hline Turbidity & 10 & 76 & 11 & 74 & 0.08 & 6.08 & 5.92 \\
\hline Total solids & 243 & 67 & 242 & 67 & 0.07 & 4.69 & 4.69 \\
\hline $\begin{array}{l}\text { Overall water-quality } \\
\text { index }\end{array}$ & & & & & & $79 \%$ & $59 \%$ \\
\hline
\end{tabular}

\section{Methodology}

The stratification in the lake was assessed by non-dimensional parameter analysis. The Lake number (Imberger 1998), an indicator of the degree of stability and mixing in the lake, was used for this analysis. $L_{\mathrm{N}}$ was calculated for Lake Tahtali, using the daily conditions in August 2006, by use of the equation:

$L_{\mathrm{N}}=\left[S_{\mathrm{t}}\left(H-h_{\mathrm{T}}\right)\right] /\left\lfloor u_{*}^{2} A_{\mathrm{s}}^{3 / 2}\left(H-h_{v}\right)\right\rfloor$

where $H$ is the total depth of the lake, $h_{\mathrm{T}}$ is the height from the bottom of the lake to the seasonal thermocline, $h_{v}$ is the height to the centre of volume of the lake, $A_{\mathrm{s}}$ is the surface area of the lake, $g^{\prime}$ is the reduced gravity, $\Delta \rho$ is the density difference between the hypolimnion and the epilimnion, $\bar{\rho}$ is the average density of the lake water, $g$ is the gravity, $A_{1}$ and $h_{1}$ are the area and the thickness of the upper layer, $A_{2}$ and $h_{2}$ are the area and the thickness of the bottom layer, $u_{*}$ is the water shear velocity due to the wind (Eq. 2), $\rho_{\mathrm{a}}$ is the density of air, $\rho_{\mathrm{w}}$ is the density of water calculated following Rubin and Atkinson (2001) (Eq. 3), $U_{(10)}$ is the wind speed $10 \mathrm{~m}$ above the water surface, and $S_{\mathrm{t}}$ is stability (Eq. 4).

$u_{*}=\left[0.0013\left(\frac{\rho_{\mathrm{a}}}{\rho_{\mathrm{w}}}\right) U_{(10)}^{2}\right]^{1 / 2}$

$\rho_{\mathrm{w}}=1,000\left[1-0.00663(T-4)^{2}\right]$

$S_{\mathrm{t}}=\frac{1}{2} g^{\prime}\left[\left[\left(A_{1} A_{2} h_{1} h_{2}\right)\left(h_{1}+h_{2}\right)\right] /\left[\left(A_{1} h_{1}\right)+\left(A_{2} h_{2}\right)\right]\right]$

After solving Eq. 1, $L_{\mathrm{N}}$ was calculated for the conditions in August 2006. Because the critical value for stratification was found to be 3 , the wind speed corresponding to this value was calculated for Lake Tahtali $\left(3 \mathrm{~m} \mathrm{~s}^{-1}\right)$. In August, $18 \%$ of the time, $L_{\mathrm{N}}$ was smaller than the critical value. In October, the percentage of the time that $L_{\mathrm{N}}$ was smaller than the critical value increased to $33 \%$.

Water quality in the lake was assessed using a waterquality index-a 100 point scale that summarizes results from a total of nine different measurements (Water-research 2006a). According to this index; the parameters dissolved oxygen (DO), faecal coliforms, $\mathrm{pH}$, biochemical oxygen demand (BOD), temperature, total phosphate, nitrates, turbidity, and total solids are used to assess the overall quality of the lake. Faecal coliform and total phosphate data were not available for Lake Tahtali; the other data were obtained from measurements conducted by IZSU. The weighting factors used in this analysis were obtained from people representing a wide range of positions at local, state, and national levels in the USA (Water-research 2006a). Saturation dissolved oxygen concentration $\left(\mathrm{mg} \mathrm{l}^{-1}\right)$ was calculated following Markofsky and Harleman (1971) as:

$\mathrm{DO}_{\text {sat }}=0.0043 T^{2}-0.36 T+14.48$

The water-quality index of Tahtali Lake was calculated as 79 (Good) for April 2006 and 59 (Medium) for August 2006, as shown in Table 1. Because the results indicated deterioration of water quality for summer period, the factors affecting water quality were further investigated within this study.

\section{Data collection and analysis}

Field observations were made in Tahtali Lake, where a multiparameter water-quality meter was deployed at monthly intervals to investigate the effects of stratification. The velocity measurements and suspended sediment concentration data were measured simultaneously when the boat was attached to a buoy in the lake. The location of the buoy is shown in the bathymetry map of Tahtali Lake 


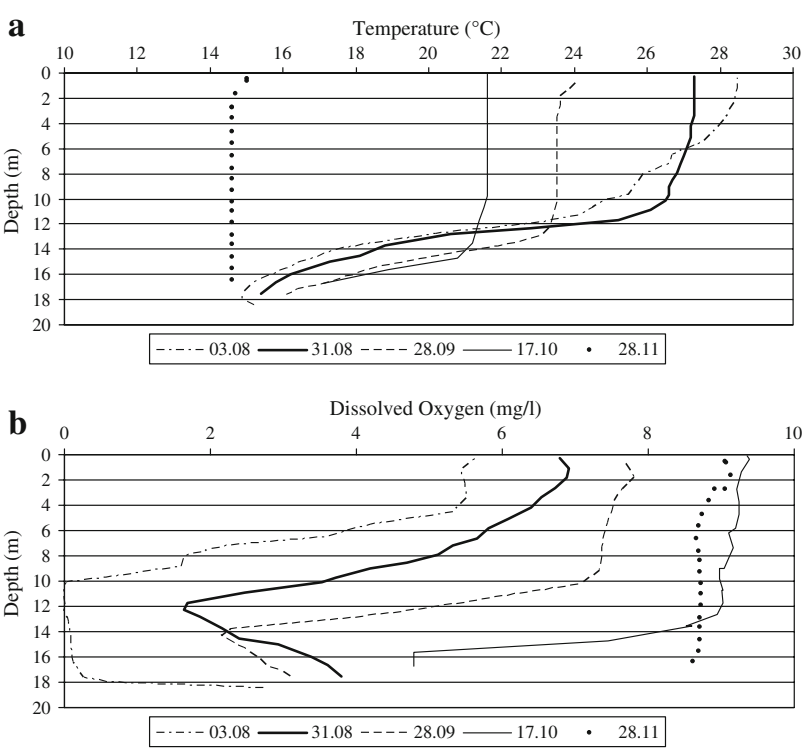

Fig. 2 The temperature (a) and dissolved oxygen (b) profiles observed during field measurements conducted once a month at the buoy

(Fig. 1). Water-quality data were measured at 1-m intervals in the vertical and were recorded at one-minute intervals.

The observed temperature profiles at the buoy are given in Fig. 2a. The depth of the water column where the buoy was located was $18 \mathrm{~m}$. As one can see in the figure, stratification was evident in August where water temperature at the surface reached $28^{\circ} \mathrm{C}$ and the thermocline started at a depth of $10 \mathrm{~m}$. In October, however, surface temperatures decreased to $21.5^{\circ} \mathrm{C}$ and the thermocline moved to a depth of $14 \mathrm{~m}$, indicating mixing of most of the water column. In November, the temperature profile was uniform throughout the water column at $\sim 15^{\circ} \mathrm{C}$.

The observed dissolved oxygen (DO) profiles are presented in Fig. 2b. Observed DO values dropped well below the standard limit of $5 \mathrm{mg} \mathrm{l}^{-1}$ (Water-research 2006b) at the thermocline, leading to the development of anoxia during the summer period. This can partly be explained by sinking of organic material produced in the epilimnion to the thermocline, where oxidization reduces the DO in the thermocline. As mixing was induced during the fall by the decrease of air temperature, and thus water temperatures at the epilimnion, an increase in DO values at the epilimnion were observed while deepening of the level of maximum DO proceeded until it reached the bottom. In November, the DO profile was uniform throughout the water column at $\sim 9 \mathrm{mg} \mathrm{l}^{-1}$. The increase in the DO concentration below the thermocline observed in August was attributed to convective circulation introduced by lateral flow from side arms of the lake. In fact, synchronized measurement of velocity profiles using an acoustic Doppler current profiler (ADCP) at the buoy depicted increase of velocities in the transverse direction close to the bed, an indication of this
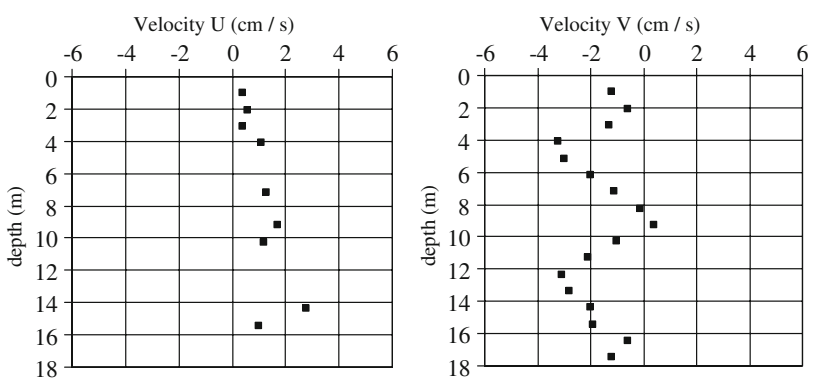

Fig. 3 Measured velocity profiles at the buoy in August, measured by the acoustic Doppler current profiler (ADCP)
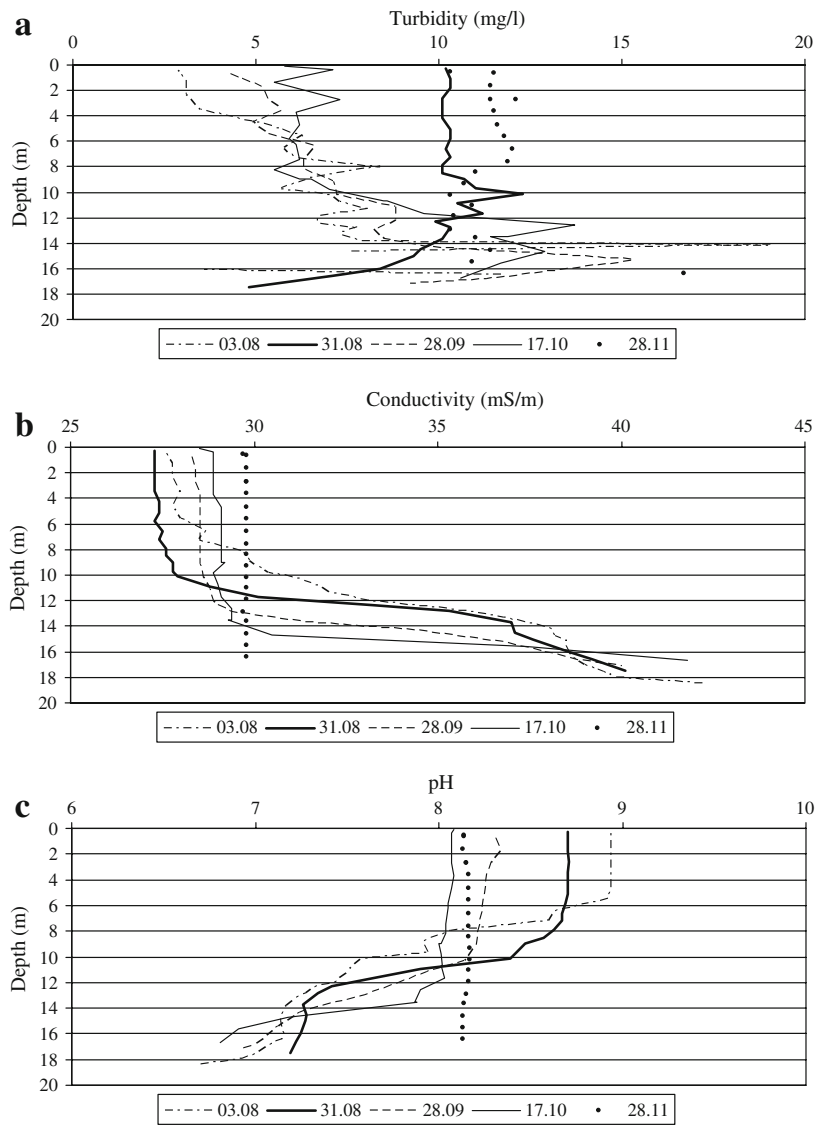

Fig. 4 The turbidity (a), electrical conductivity (b), and $\mathrm{pH}$ (c) profiles observed during field measurements conducted once a month at the buoy

flow from the side arms (Fig. 3). Details of velocity measurements are provided in Çalışkan and Elçi (2007).

The variation of the turbidity profiles measured by the water-quality meter is presented in Fig. 4a. Turbidity peaks are found mostly in the thermocline region. Turbidity increases are closely related to the location of the maximum density gradient in the vertical, where low turbulence is expected because of stabilization of the water column. A noticeable increase in turbidity toward the bottom of the lake on 17.10 .06 was probably because of the effect of the 
relatively cold sediment-laden water flowing into the lake after a rain event.

The observed conductivity and $\mathrm{pH}$ profiles are presented in Figs. 4b, c. A decrease in $\mathrm{pH}$ in the lower layers of the stratified lake was observed due to accumulation of $\mathrm{CO}_{2}$, because no light could penetrate through the thermocline to the hypolimnion during the summer period and plants could not consume $\mathrm{CO}_{2}$ by photosynthesis. Furthermore, $\mathrm{CO}_{2}$, released as a result of decomposition of organic matter in the hypolimnion dissolves in water to form carbonate ions, increasing the ion concentration. This increase in the ion concentration was reflected as an increase of electrical conductivity measured in the hypolimnion during the summer period. In November, the $\mathrm{pH}$ and the electrical conductivity profiles were uniform throughout the water column at $\sim 8$ and $\sim 30 \mathrm{~ms} \mathrm{~m}^{-1}$, respectively.

Besides the measurements conducted in the lake once a month, the water-quality meter was left at a depth of $\sim 11 \mathrm{~m}$ (thermocline) during August (no mixing), October (partial mixing), December (mixed), and April (partial mixing). The variations of DO data recorded internally every half an hour, with air temperature recorded at the weather station, are given in Figs. 5, 6, and 7 for August, October, and December, respectively.

As can be seen in Fig. 5, an increase was observed in the DO observations, with DO values increasing from 0 to $1.8 \mathrm{mg} \mathrm{l}^{-1}$ (day 21). The air temperature data collected at the weather station for the same measurement period indicated that air temperatures decreased from 40.1 to $35.6^{\circ} \mathrm{C}$, with a $4.5^{\circ}$ difference between highest daytime temperatures (maximum), and from 25 to $21.9^{\circ} \mathrm{C}$, with a $3.1^{\circ}$ difference between lowest overnight temperatures (minimum). The air-temperature difference observed during the day was $13.7^{\circ}$ whereas this difference was $1.7^{\circ}$ for water temperature.

In October (Fig. 6), a similar increase in DO observations occurred, with DO values increasing from 6.6 to $11 \mathrm{mg} \mathrm{l}^{-1}$ (day 10). The data collected at the weather station for the same measurement period indicated that air temperatures decreased from 25.5 to $23^{\circ} \mathrm{C}$, with a $2.5^{\circ}$ difference between maximum temperatures, and from 18 to $14.8^{\circ} \mathrm{C}$, with a $3.2^{\circ}$ difference between minimum values. The air-temperature difference observed during the day was $8.1^{\circ}$ whereas this difference was $2^{\circ}$ for water temperature.

The data observed in December (Fig. 7) showed DO values increased from 9.7 to $10.5 \mathrm{mg} \mathrm{l}^{-1}$ (day 28). The data collected at the weather station for the same measurement period indicated that air temperatures decreased from 12 to $8.4^{\circ} \mathrm{C}$, with a $3.6^{\circ}$ difference between maximum temperatures, and from 5.7 to $0^{\circ} \mathrm{C}$, with a $5.7^{\circ}$ difference between minimum values. The air-temperature difference observed during the day was $8.5^{\circ}$ whereas this difference was $1^{\circ}$ for water temperature.

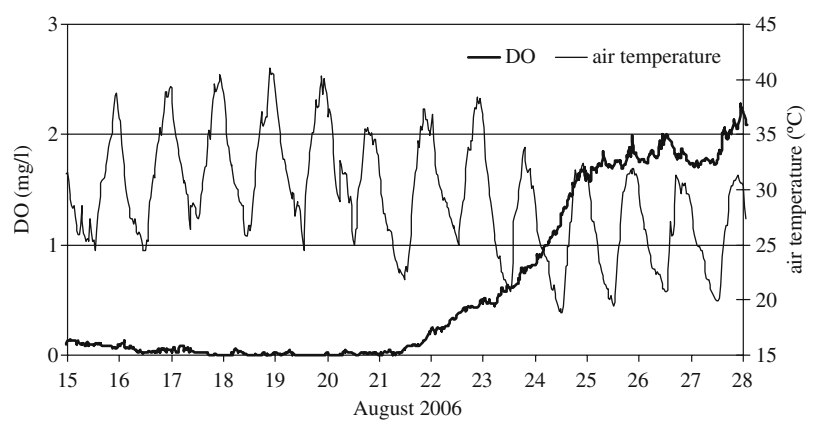

Fig. 5 Variation of DO with air temperature in August 2006. The water-quality meter was at a depth of $\sim 11 \mathrm{~m}$ (thermocline)

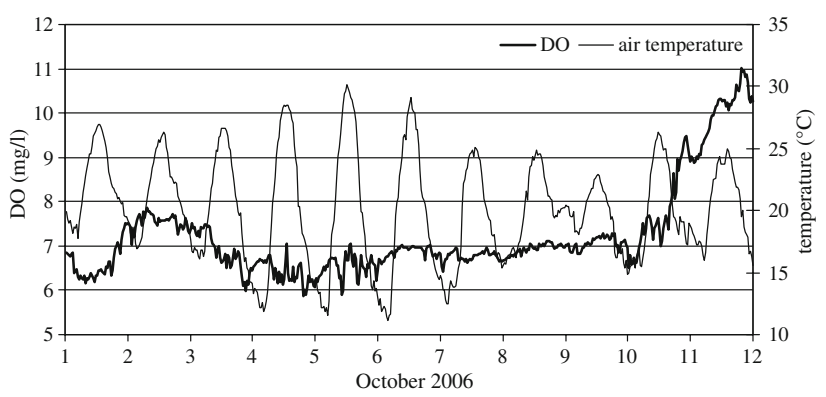

Fig. 6 Variation of DO with air temperature in October 2006. The water-quality meter was at a depth of $\sim 11 \mathrm{~m}$

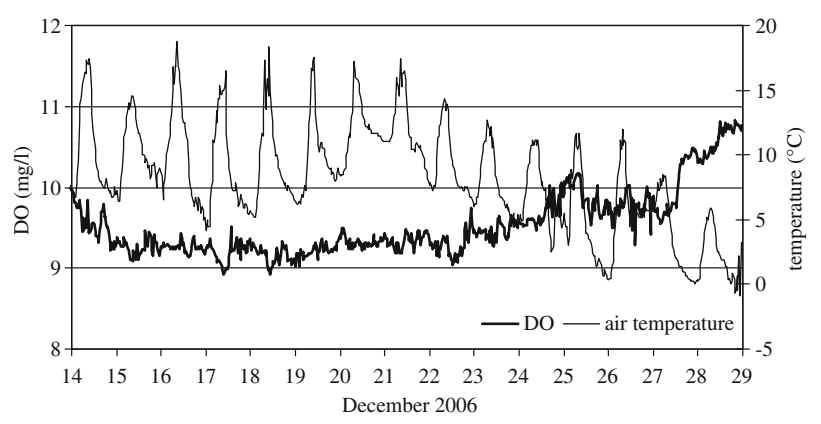

Fig. 7 Variation of DO with air temperature in December 2006. The water-quality meter was at a depth of $\sim 11 \mathrm{~m}$

One day before the increases observed in the values of DO concentration in both August and October, the wind speed values were measured as 4.5 and $5 \mathrm{~m} \mathrm{~s}^{-1}$ leading to $L_{\mathrm{N}}$ of 3 . However, because $L_{\mathrm{N}}$ was equal to 3 at other times before the increases, $L_{\mathrm{N}}$ can not be accepted as a sufficient indicator alone and the direct effect the other parameters including air and water temperatures should be incorporated into equations describing the behaviour of the DO.

Figure 8 shows the variation of turbidity, recorded by the water-quality meter, with the wind speed, measured at the weather station, for August. Since no rain was recorded in August, the local peaks (days 19, 20 and 23) observed in 


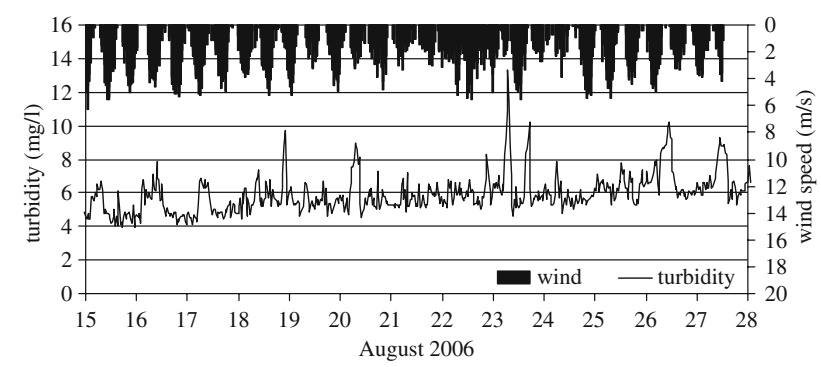

Fig. 8 Variation of recorded turbidity and wind speed in August 2006. The water-quality meter was left at a depth of $\sim 11 \mathrm{~m}$ (thermocline)

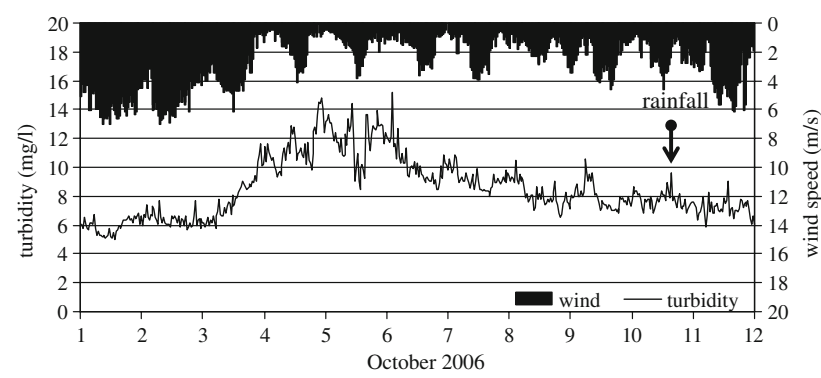

Fig. 9 Variation of recorded turbidity and wind speed in October 2006. The water-quality meter was left at a depth of $\sim 11 \mathrm{~m}$

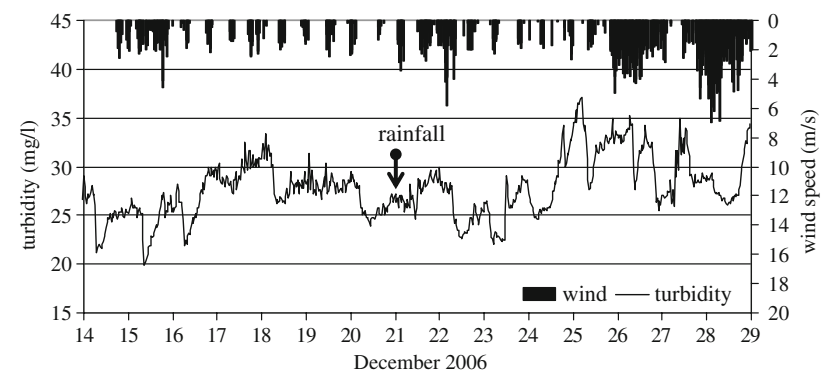

Fig. 10 Variation of recorded turbidity and wind speed in December 2006. The water-quality meter was left at a depth of $\sim 11 \mathrm{~m}$

turbidity measurements can be attributed to variation of wind gusts before those days. Waves are formed due to shear stresses induced by wind promoting resuspension in the water column. In October (Fig. 9), turbidity increased from 6 to $14 \mathrm{mg}^{-1}$ after the high wind gusts were observed (days 2 and 3) and no rain was recorded before those days either. In December (Fig. 10), as complete mixing of the water column was reached, high turbidity values were observed compared with the other months. Peak turbidity values increased from 26 to $36 \mathrm{mg}^{-1}$ (day 25 ) and can be attributed to the high wind gusts observed one day before and $4 \mathrm{~mm}$ of rain measured three days before the peak turbidity was measured.

\section{Statistical analysis}

Multivlariate analysis was carried out on a data matrix of seven variables (air temperature, wind speed, wind direction, lagged wind speed, humidity, evaporation, and temperature difference). The purpose of this analysis was to determine which of these variables were influential in modelling water-quality parameters such as $\mathrm{pH}$, conductivity, DO, and turbidity. Rainfall data were excluded from the analysis, because it rained only twice during the period of the observations and thus data were insufficient to include in the analysis. Wind-speed data were lagged by $24 \mathrm{~h}$, and 24-h differences in air temperatures were included in the model. Time intervals for lags and differences were decided on the basis of visual interpretations of data time series. Models developed by principal-component analysis (PCA), and partial least-squares (PLS) analysis expressed the correlations between different variables which were used to identify the most influential variables. Simca-P 10.5 software (Umetrics 2003) was applied for PCA and PLS modelling.

PCA shows the correlation structure of data matrix (X) approximated by a matrix product of lower dimension $\left(\mathrm{TP}^{\prime}\right)$ plus a matrix of residuals $(\mathrm{E})$ :

$\mathrm{X}=\overline{\mathrm{X}}+\mathrm{TP}^{\prime}+\mathrm{E}$

where (T) is a matrix of scores summarizing the $X$ variables and $(\mathrm{P})$ is a matrix of loadings showing the influence of the variables, and (E) is the matrix of residuals showing the deviations between the original and projected values (Umetrics 2003).

Principal-component analysis (PCA), an efficient tool for investigating the interconnection of the datasets, was applied to the water-quality data. In the winter model, water temperature was found to be inversely correlated with $\mathrm{pH}, \mathrm{DO}$, turbidity, and conductivity.

Partial least-squares (PLS) analysis extracts the degree of explanation of the dependent $Y$ variables (water-quality parameters) for each independent $X$ variable (air temperature, wind speed, wind direction, lagged wind speed, humidity, and temperature difference) and the degree of correlation between the $X$ variables as follows:

$Y=f(X)+\mathrm{E}$

PLS modelling consists of simultaneous projections of both the $X$ and $Y$ spaces. The structure of the PLS modelling consists of Eqs. 6-9.

$Y=\bar{Y}+\mathrm{UC}^{\prime}+F$

$\mathrm{U}=\mathrm{T}+\mathrm{H}$

where, $(\mathrm{U})$ is a matrix of scores summarizing the $Y$ variables and (W) is a matrix of weights expressing the correlation between $X$ and $U(Y)$. (C) is a matrix of weights 
Table 2 Coefficients used in the PLS model for Tahtali Lake

\begin{tabular}{|c|c|c|c|c|c|}
\hline & $T_{\mathrm{w}}$ & $\mathrm{pH}$ & Turbidity & DO & Conductivity \\
\hline \multicolumn{6}{|l|}{ Winter model } \\
\hline Air temperature & 0.49 & 0.08 & -0.37 & -0.44 & -0.45 \\
\hline $\mathrm{dT}$ & -0.11 & 0.12 & 0.03 & 0.09 & 0.00 \\
\hline Humidity & 0.23 & 0.48 & 0.10 & -0.18 & -0.44 \\
\hline Wind & -0.13 & 0.10 & 0.12 & 0.08 & 0.09 \\
\hline Lagged wind & -0.26 & 0.27 & 0.15 & 0.28 & 0.03 \\
\hline Constant & 13.27 & 99.39 & 6.34 & 21.48 & 115.09 \\
\hline \multicolumn{6}{|l|}{ Summer model } \\
\hline Air temperature & 0.37 & 0.28 & -0.34 & -0.08 & -0.33 \\
\hline $\mathrm{dT}$ & -0.15 & -0.04 & -0.02 & 0.02 & 0.11 \\
\hline Humidity & 0.36 & 0.36 & 0.30 & 0.30 & -0.38 \\
\hline Wind & -0.19 & -0.19 & 0.14 & 0.09 & 0.18 \\
\hline Lagged wind & -0.20 & -0.20 & 0.12 & 0.09 & 0.19 \\
\hline Constant & 23.07 & 152.57 & 4.99 & 0.54 & 37.65 \\
\hline \multicolumn{6}{|l|}{ Fall model } \\
\hline Air temperature & 0.66 & 0.13 & 0.29 & -0.33 & -0.21 \\
\hline $\mathrm{dT}$ & -0.05 & -0.13 & 0.01 & -0.20 & 0.20 \\
\hline Humidity & 0.63 & 0.12 & 0.67 & -0.36 & -0.26 \\
\hline Wind & -0.10 & -0.18 & 0.02 & -0.08 & 0.12 \\
\hline Lagged wind & 0.01 & 0.00 & 0.00 & 0.09 & -0.10 \\
\hline Constant & 29.87 & 141.47 & 6.90 & 18.58 & 104.36 \\
\hline
\end{tabular}

$\mathrm{dT}$ denotes the daily temperature change, $T_{\mathrm{w}}$ is the water temperature, and DO is the dissolved oxygen

expressing the correlation between $Y$ and $T(X)$. $(\mathrm{F})$ and $(\mathrm{H})$ are the matrices of residuals. The first component of the PLS model explains more of the variance than the second component, so only coefficients of the first component are given here.

PLS analysis was used to investigate the impact of the different variables on each particular water-quality parameter. The relations were analyzed with the help of the coefficient and variable importance plots. The coefficients used in the PLS model are given in Table 2. Wind direction and evaporation were found as insignificant compared with other relevant variables and are not shown in the table. According to the results from PLS analysis, in winter, air temperature and one-day-lagged wind speed were the most dominant variables affecting observed dissolved oxygen and turbidity values. However, in summer and in fall, humidity and air temperature were the most dominant variables.

Figure 11 depicts the correlation structures between the independent variables $(X)$ and the dependent water-quality parameters $(Y)$. Variables situated along the same directional axis correlate with each other. The weights for the $X$ variables, denoted $w$, indicate how much they participate in the modelling of $Y$ in a relative sense and the weights of the $Y$ variables, denoted $c$, indicate which $Y$ variables are modeled. The winter model extracted two significant
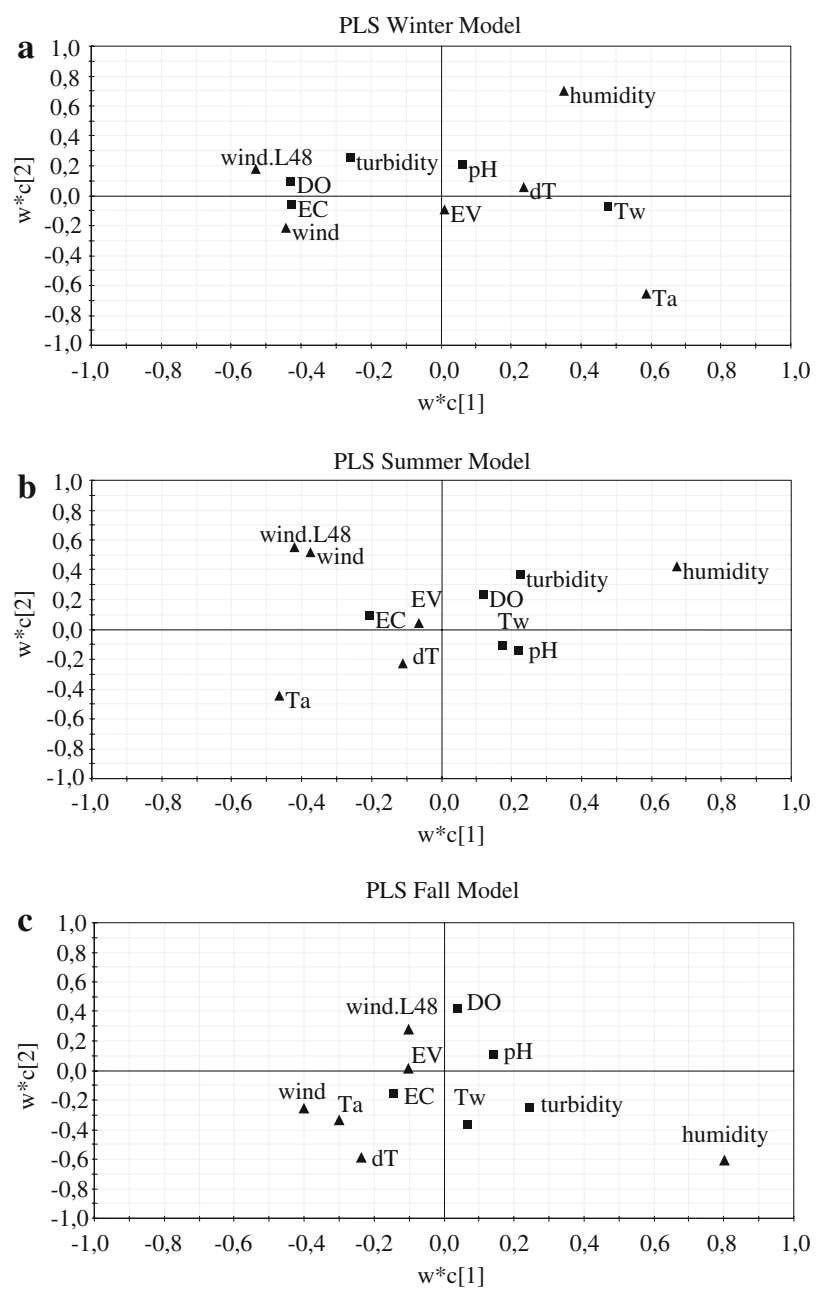

Fig. 11 The relationships between the dependent $Y$ and independent $X$ variables as obtained from PLS analysis of the winter (a), summer (b), and fall (c) data. Variables situated closely are positively correlated and when placed at the outer ends are negatively correlated. In the figure, $T_{a}$ denotes the air temperature, $d T$ is daily temperature change, $E V$ is evaporation, $E C$ is conductivity, $D O$ is dissolved oxygen, $T_{\mathrm{w}}$ is water temperature, and $24 \mathrm{~h}$ lagged wind speed is represented by WS.L48. $w$ on the axis indicates the weights for the $X$ variables in the modelling of $Y$, and $c$ indicates which $Y$ variables are modelled

components from the data set explaining $52 \%$ of the variance in the observed water-quality parameters (Fig. 11a). The summer model explained $71 \%$ of the variance using two components (Fig. 11b), and the fall model explained $72 \%$ of the variance using two components (Fig. 11c). Results indicated that air temperature, lagged wind speed, and humidity are the influential parameters affecting variations in water-quality parameters.

\section{Conclusions}

It was observed that stratification alters velocity profiles drastically and thus affects water quality in the reservoir. 
Therefore, the sensitivity of water-quality parameters to wind and stratification was investigated; this is useful for mitigation of pollution problems and for prediction of reservoir water quality and development of maintenance schemes. The water-quality parameters are found to be correlated with temperature profiles in the vertical except at the thermocline. It was observed that the thermocline behaved as a barrier for dissolved oxygen, which dropped well below the standard limit of $5 \mathrm{mg}^{-1}$ at the thermocline leading to the development of anoxia. It was concluded that Lake number alone is not a sufficient parameter to assess the behaviour of DO in the water column, and variations in air temperature and humidity must be included in the analysis. Other parameters leading to changes in concentrations of dissolved oxygen and sediment concentration were investigated by statistical analysis of observed data.

Turbidity profiles were highly affected, with stratification where suspended sediment concentrations increased at the thermocline. High wind gusts increased the turbidity in the water column although the affect was temporary. As expected, high turbidity was observed after rain events, because of erosion of the lake banks. Although rainfall data were excluded in the statistical analysis, because of lack of rainfall, inclusion of rainfall data is recommended in the models predicting turbidity.

Multivariate analysis investigated the impact of the different variables including air temperature, wind speed, wind direction, and lagged wind speed on each particular water-quality parameter. The relationships were analyzed with the help of the coefficient and variable importance plots. Wind direction and evaporation were found to have no influence on water-quality parameters. One-day lagged wind speed influenced the parameters more than average wind speed or gust values measured at the site. Fall, summer, and winter models described the correlation structures between independent (meteorological) and dependent (water-quality) parameters. The winter model extracted two significant components from the data set explaining $52 \%$ of the variance in the observed waterquality parameters The summer model explained $71 \%$ and the fall model explained $72 \%$ of the variance using two components.
Results of the statistical analysis showed that air temperature, lagged wind speed, and humidity are the influential parameters affecting variations in water-quality parameters. Therefore in such analysis the non-dimensional parameters water temperature and wind alone do not suffice, and variations in water quality structure should be evaluated by new approaches considering other meteorological factors.

Acknowledgments This study was funded by research grants from the European Commission within project no. 028292 (RESTRAT) and Tubitak within project no. 104Y323. I also would like to thank to my graduate students Anıl Çalışkan and Ramazan Aydın and the staff of Izmir Water and Sewage Authority (IZSU) for their contributions during collection of the data.

\section{References}

Bell VA, George DG, Moore RJ, Parker J (2006) Using a 1-D mixing model to simulate the vertical flux of heat and oxygen in a lake subject to episodic mixing. Ecol Modell 190:41-54

Bonnet MP, Poulin M, Devaux J (2000) Numerical modeling of thermal stratification in a lake reservoir. Methodology and case study. Aqua Sci 62:105-124

Çalışkan A, Elçi, Ş (2007) Investigation of the hydrodynamic structure in a stratified lake: Tahtali. Proceedings of 32nd congress of IAHR, Venice, Italy. Theme A1.a.Hydrodynamics of lakes and reservoirs Paper \#320, $16 \mathrm{p}$

Hamilton DP, Schladow GS (1997) Prediction of water quality in lakes and reservoirs. Part I-model description. Ecol Modell 96:91-110

Imberger J (1998) Physical processes in lakes and oceans, AGU coastal and estuarine studies, vol 54, pp 1-18

Markofsky M, Harleman DRF (1971) Predictive model for thermal stratification and water quality in reservoirs. Technical Report 134, MIT, Boston

Rubin H, Atkinson J (2001) Environmental fluid mechanics. Marcel Dekker, NY, 728 p

Stefan HG, Fang X (1994) Dissolved oxygen model for regional lake analysis. Ecol Modell 71:37-68

Umetrics (2003) Statistical notes in Simca-P 10.5 help menu

Water-research (2006a) Calculating NSF water-quality index. Online: available at http://www.water-research.net/watrqualindex/index. htm

Water-research (2006b) Partial listing of general surface water physical and chemical standards. Online: available at http://www. water-research.net/surfacewater.htm 